\title{
Generalizable Strategy for Engineering Protein Particles with pH- Triggered Disassembly and Recoverable Protein Functionality
}

\author{
Tomoya Suma, Jiwei Cui, Markus Müllner, Yi Ju, Junling Guo, Ming Hu, and Frank Caruso*
}

ARC Centre of Excellence in Convergent Bio-Nano Science and Technology, and the Department of Chemical and Biomolecular Engineering, The University of Melbourne, Parkville, Victoria 3010, Australia

\begin{abstract}
Protein particles are promising candidates for therapeutic delivery. In this study, we report a generalizable strategy to assemble a series of proteins into $\mathrm{pH}$-cleavable protein particles that recover protein functionality after disassembly. Our strategy uses an acid-labile reversible cross-linker based on maleic acid amide chemistry, which allows the cross-linking of proteins and releases unmodified proteins upon cleavage, causing minimal loss of protein functionality. The protein particles can be rapidly disassembled at a mildly acidic $\mathrm{pH}(<6.5)$ and inside cells with negligible cytotoxicity. Furthermore, cleavage of the cross-linker led to above $97 \%$ recovery of enzymatic activity, as evidenced by using glucose oxidase. This facile and robust strategy to engineer $\mathrm{pH}$-cleavable protein particles may provide a new platform for therapeutic protein delivery as well as for small molecule drug and nucleic acid delivery.
\end{abstract}

Proteins are one of the main components of living organisms, which are sophisticated structures that have specific functions, such as signaling, transportation of biological molecules and catalysis. ${ }^{1}$ The highly developed functionality of proteins has attracted intense interest to exploit them as building blocks for drug carriers as well as therapeutic drugs. ${ }^{2-6}$ In this context, a variety of approaches for the fabrication of protein particles has been developed; these include emulsion formation, ${ }^{7,8}$ precipitation, ${ }^{9}$ coacervation, ${ }^{10,11}$ spray drying, ${ }^{12}$ and templatedirected assembly. ${ }^{13-15}$ This versatile toolbox has allowed the fine-tuning of the properties of protein particles (e.g., size, shape and surface chemistry), depending on the desired application. However, existing studies on protein particles are mainly focused on relatively robust proteins with limited functionality. The development of a general strategy for the preparation of functional protein particles would expand their future applications.

The preparation of protein particles commonly involves cross-linking, as pure protein particles are often unstable, and thus quickly dissolve back into the constituent proteins. However, the majority of currently available crosslinking agents are based on N-hydroxy succinimide (NHS), 1-ethyl-3-(3-dimethylaminopropyl) carbodiimide (EDC), maleimide, or glutaraldehyde chemistry, which all result in permanent modification of the amine or sulfhydryl group of the proteins. ${ }^{16-18}$ These modifications of proteins usually result in a reduction of protein activity. ${ }^{19-21}$ In addition, the permanent pendant groups may alter the native structure of proteins, thus causing them to appear as foreign substances, possibly resulting in the stimulation of undesired immune responses against the modified proteins. ${ }^{5,18,22}$ Thus, a reversible cross-linking approach, which cleaves and regenerates the unmodified proteins upon a certain stimulus, is highly desirable. ${ }^{6}$ In this regard, mildly acidic $\mathrm{pH}$ is an attractive physiological trig- ger, as it is relevant, for example, in intracellular endosomes/lysosomes, ${ }^{23}$ skin, ${ }^{24}$ and tumor tissues. ${ }^{25}$ The integration of a $\mathrm{pH}$-triggered disassembly mechanism into protein particles can lead to further enhancement in therapeutic efficiency, as it allows the target-specific release of cargos. Furthermore, the disintegration of protein particles into the constituent proteins will help the excretion of protein particles from the body, thereby minimizing the risk of cumulative toxicity.

Herein, we describe a robust strategy to integrate the mechanism of $\mathrm{pH}$-triggered disassembly into protein particles while retaining their enzymatic activity after cleavage using a $\mathrm{pH}$-responsive cross-linker based on maleic anhydride chemistry (Figure 1). The maleic acid amide (MAA) linkage, which is formed from maleic anhydride derivatives and amine groups, is relatively stable above neutral $\mathrm{pH}$, but cleavable in mildly acidic environments (Figure 1c). ${ }^{26-31}$ The responsiveness to acidic $\mathrm{pH}$ can be controlled by substitution around the carbon double bond of maleic anhydride derivatives, potentially allowing for further tuning of the $\mathrm{pH}$-sensitivity. ${ }^{26}$ In addition, MAA leaves no trace upon cleavage and fully regenerates the pristine amine groups of proteins and therefore their enzymatic activity. In this report, a series of proteins were first immobilized into calcium carbonate $\left(\mathrm{CaCO}_{3}\right)$ particles via a coprecipitation method and subsequently crosslinked with the $\mathrm{pH}$-sensitive MAA-based cross-linker. The coprecipitation method allows the preparation of $\mathrm{CaCO}_{3}$ /protein hybrid particles with high loading amounts of protein, where sizes from a few micrometers to as low as $100 \mathrm{~nm}$ have been reported..$^{32-34}$ Furthermore, the $\mathrm{CaCO}_{3}$ template can be readily removed by mild treatment with ethylenediamine tetraacetic acid (EDTA), rendering this method advantageous to incorporate functional proteins. ${ }^{32,33}$ Dissolving the $\mathrm{CaCO}_{3}$ template particles yielded protein particle replicas (Figure $1 \mathrm{~b}$ ). These 
protein particles are able to disassemble in mildly acidic environments and inside cultured cells. Furthermore, the MAA-based cross-linking has negligible influence on enzymatic activity after cleavage.

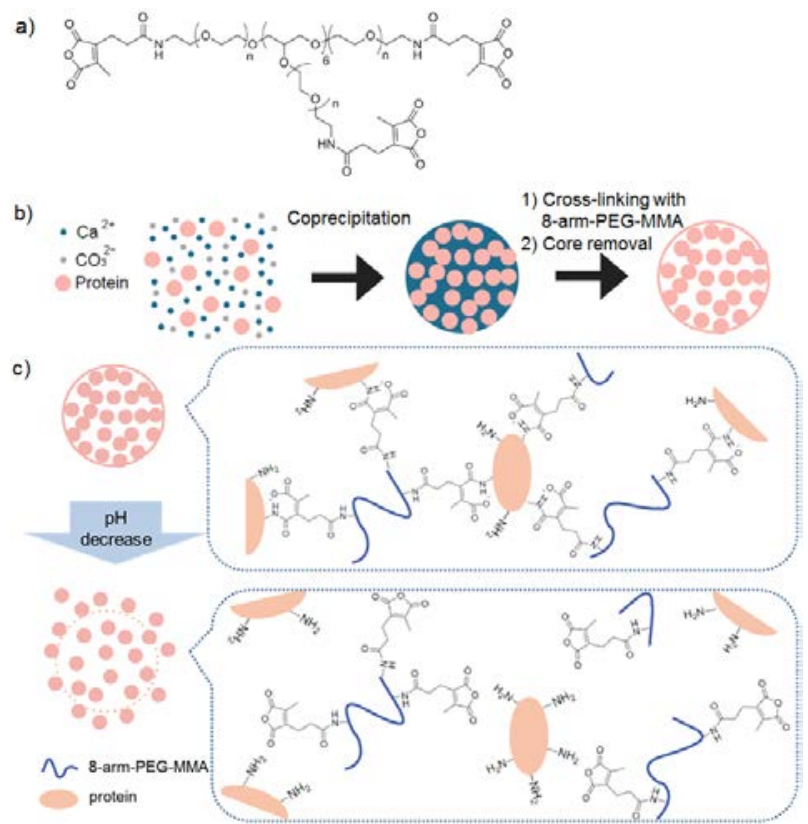

Figure 1. (a) Chemical structure of the acid-labile crosslinker, 8-arm-PEG-methylmaleic anhydride (8-arm-PEGMMA). (b) Preparation of protein particles via coprecipitation of calcium carbonate and protein, followed by crosslinking with 8 -arm-PEG-MMA and core removal by EDTA. (c) $\mathrm{pH}$-Rresponsive degradation of the protein particles.

The acid-labile cross-linker was synthesized from 8arm-PEG-amine (10 kDa) and carboxy dimethylmaleic anhydride (CDM), yielding an 8-arm-PEG with terminal methylmaleic anhydride (MMA) moieties on each arm (Supporting Information, Figure $\mathrm{S}$ ). ${ }^{1} \mathrm{H}$ NMR measurements revealed the quantitative conversion of terminal amine groups to MMAs (Supporting Information, Figure S2). CDM was selected as a model maleic anhydride derivative because the MAA linkage from di-substituted maleic anhydride derivatives was reported to show immediate sensitivity to an acidic $\mathrm{pH}^{2 .{ }^{2-31}}$ Additionally, the backbone is composed of PEG with a molecular weight of $10 \mathrm{kDa}$, which is known to be highly biocompatible and likely to be excreted by the kidneys. ${ }^{35}$

Human serum albumin (HSA) was coprecipitated together with calcium chloride and sodium bicarbonate to obtain protein-loaded $\mathrm{CaCO}_{3}$ particles. HSA was selected as a model protein because of its abundance and potential use as a therapeutic carrier, as demonstrated for the delivery of anticancer drugs and imaging agents. ${ }^{36}$ The immobilized HSA was cross-linked in aqueous solution via the addition of 8-arm-PEG-MMA. Subsequently, the template was removed with EDTA (10o mM, pH 7.4) (Figure 1). The preparation of HSA particles was confirmed by differential interference and fluorescence microscopy (Figure 2a, b). The fluorescence distribution within each particle suggested the entrapment of proteins in the particles (Figure 2a). However, sectioning of the protein particles revealed a slightly stronger fluorescence at the periphery of the particles (Supporting Information, Figure S3), suggesting that the cross-linking is more efficient on the periphery of the particles, as the cross-linker might only diffuse slowly into the inorganic $\mathrm{CaCO}_{3}$ template particles. Transmission electron microscopy (TEM) micrographs further underlined the formation of spherical particles with denser protein networks around the surface (Figure 2c, d), which is consistent with the observation by deconvolution microscopy (Figure $\mathrm{S}_{3}$ ). With amino groups consumed for cross-linking by MMA moieties, the zeta potential of HSA particles was $-37 \pm 3.5 \mathrm{mV}$ (10 mM phosphate buffer, $\mathrm{pH}$ 7.4). Furthermore, the HSA content in each particle was determined to be $2.1 \pm 0.6 \mathrm{pg}$, based on the number of HSA particles counted by flow cytometry and the concentration of HSA measured from the fluorescence intensity in solution after disassembly of the HSA particles under acidic conditions. (AF488 fluorescence was not affected by the acid treatment - data not shown.)
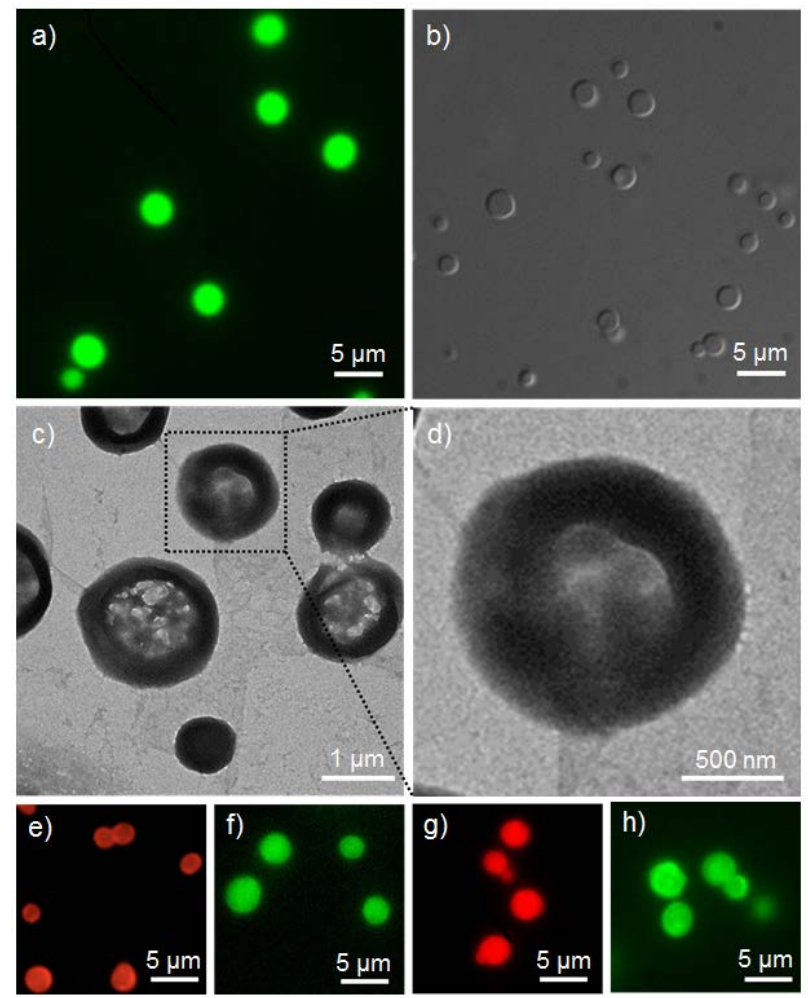

Figure 2. (a) Fluorescence microscopy image, (b) differential interference contrast (DIC) image, (c) TEM micrograph, and (d) magnified TEM image of HSA particles. (e-h) Fluorescence microscopy images of protein particles prepared from a series of proteins: (e) glucose oxidase, (f) ovalbumin, (g) catalase, and (h) $\beta$-galactosidase. Proteins were labeled with either AF488 (green) or Alexa Fluor 555 (AF555, red) prior to particle formation.

To examine the versatility of this method to generate particulate formulations of proteins, a series of functional 
proteins, including glucose oxidase (GOD), ovalbumin (OVA), catalase (CAT) and $\beta$-galactosidase ( $\beta$-GAL), were used. All of these proteins were assembled into spherical protein particles that showed similar morphologies to the HSA particles (Figure ze-h). Tuning of the size of protein particles may be required for different applications, from depot formulation to immunological application and targeting of different organs. ${ }^{37-41}$ In this regard, the diameter of HSA particles can be readily adjusted using micrometer to sub-micrometer-sized $\mathrm{CaCO}_{3}$ templates (Supporting Information, Figures $\mathrm{S}_{4}$ and $\mathrm{S}_{5}$ ). These various protein particles highlight the modular approach of producing protein particles using 8-arm-PEG-MMA as a cross-linker.

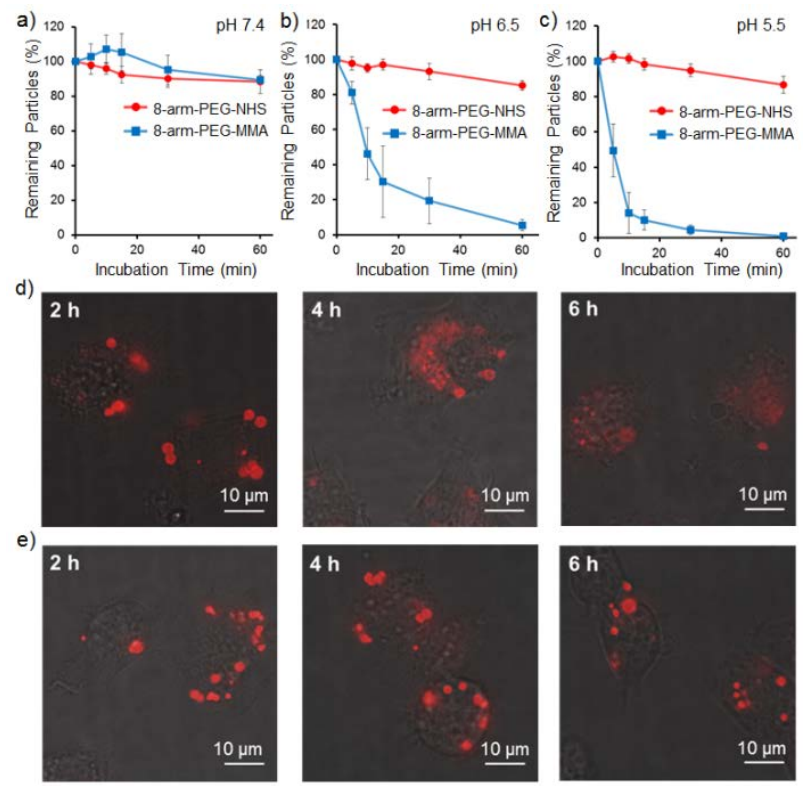

Figure 3. (a-c) Disassembly kinetics of HSA particles as a function of time via incubation of HSA particles cross-linked with 8-arm-PEG-MMA or 8-arm-PEG-NHS in (a) pH 7.4, (b) 6.5 , or (c) 5.5 buffered solution. The results are shown as the mean and standard error obtained from five measurements. (d,e) Representative deconvolution microscopy images of the intracellular disassembly of HSA particles cross-linked with (d) 8-arm-PEG-MMA or (e) 8-arm-PEG-NHS.

To assess the $\mathrm{pH}$-triggered disassembly of the HSA particles based on the cleavage of the MAA linkage, Alexa Fluor 488 (AF488)-labeled HSA particles were incubated in different $\mathrm{pH}$ conditions and changes in the number of the HSA particles were monitored by flow cytometry (Figure 3a, b, c). Notably, the HSA particles showed rapid disassembly at the mildly acidic $\mathrm{pH}$ of 6.5 . More rapid disassembly was observed at $\mathrm{pH} 5.5$, resulting in almost complete disassembly after 60 min of incubation. In contrast, the HSA particles were relatively stable at the physiological $\mathrm{pH}$ of 7.4 for the same time period. The HSA particles cross-linked by the non-acid-labile 8-arm-PEGNHS cross-linker (Supporting Information, Figure S6) showed no changes in the number of particles at both neutral and acidic $\mathrm{pH}$ (Figure 3a, b, c). These results highlight the $\mathrm{pH}$-triggered destabilization and disassembly of the HSA particles, which is due to cleavage of the MAA linkages in response to acidic $\mathrm{pH}$. The disassembly of the HSA particles is slightly quicker than the reported results for the cleavage of MAA linkages formed from dimethylmaleic anhydride derivatives. ${ }^{26-31}$

Next, the intracellular disassembly profile of the HSA particles was examined by deconvolution microscopy, with non-acid-labile HSA particles cross-linked with 8arm-PEG-NHS as a control. To examine the intracellular disassembly of the protein particles, two types of model cell lines were selected: i.e., human lung adenocarcinoma cell (A549), which have potential application in cancer treatment; and bone marrow derived murine dendritic cell (JAWS II), which have potential application in vaccination and immunotherapy. ${ }^{40,41}$ Deconvolution microscopy revealed almost no association and internalization of HSA particles with A549 cells (data not shown). The low cellular association is possibly due to the cross-linker, 8arm-PEG-MMA, which might contribute to the surface properties of the HAS particles and hence reduce interaction with non-phagocytic cells, such as A549 cells. Next, JAWS II cells were used for the investigation of intracellular behavior of HSA particles. JAWS II cells were incubated with AF555-labeled HSA particles at a particle-to-cell ratio of approximately 10. After incubation, the timedependent intracellular disassembly was followed using deconvolution microscopy at different time points. Representative images of cells incubated with the acid-labile or non-acid-labile HSA particles are shown in Figure $3 \mathrm{~d}$ and 3e, respectively. For acid-labile HSA particles, particles were still observed after $2 \mathrm{~h}$. After $4 \mathrm{~h}$, the red fluorescence spread inside the cells, suggesting that some of the HSA particles had disassembled. After $6 \mathrm{~h}$, almost all of the red fluorescence had spread inside the cells. This observation strongly suggests that the HSA particles crosslinked with 8-arm-PEG-MMA were able to disassemble intracellularly, using the acidification in the endosome/lysosome as a trigger. ${ }^{23}$ Although the disassembly of the HSA particles may assist the leakage of HSA to the cytoplasm, as suggested by the intracellular-diffused fluorescence, the translocation from endosome/lysosome components to the cytoplasm still may be limited as the particles are composed only of non-endosomolytic materials (i.e., HSA and PEG). In contrast, HSA particles crosslinked with 8-arm-PEG-NHS showed that most of the red fluorescence was still observed as micrometer-sized round spots inside the cells, even after $6 \mathrm{~h}$. The remaining integrity of the HSA particles highlights the essential role of MAA linkages for the intracellular disassembly of the HSA particles. It is noted that the HSA particles showed negligible cytotoxicity against JAWS II cells for all tested conditions, including that used for the intracellular disassembly study, as evidenced by XTT assays (Supporting Information, Figure $\mathrm{S}_{7}$ ).

Modification of protein amine groups often reduces the enzymatic activity of the proteins; hence the regeneration of intact proteins with recovered enzymatic activity would be advantageous. The effect of modification by 8 arm-PEG-MMA on the enzymatic activity was investigat- 
ed using a model protein, GOD. First, GOD was either modified with an acid-labile 8-arm-PEG-MMA or the same amount of 8-arm-PEG-NHS as a non-acid-labile control. The enzymatic activity of GOD was evaluated by monitoring the production of oxidized compounds of odianisidine as a result of a coupled reaction in a solution containing glucose and horseradish peroxidase. ${ }^{42}$ The modification with 8-arm-PEG-MMA led to approximately a $25 \%$ reduction of the enzymatic activity of GOD at $\mathrm{pH}$ 7.4 (Figure $4 \mathrm{a}$ ), which was consistent with previously reported results that showed the reduction of GOD activity after the conjugation of PEG via amide bonds. ${ }^{20} \mathrm{~A}$ similar level of reduction of enzymatic activity was also observed when GOD was modified with 8-arm-PEG-NHS. The decreased enzymatic activity of GOD was probably due to the modification of the amine groups at catalytic sites, resulting in the lower affinity to substrate molecules. ${ }^{20}$ The enzymatic activity of GOD modified with 8-arm-PEGMMA became comparable to unmodified GOD after incubation at acidic $\mathrm{pH}$ (5.1) (Figure $4 \mathrm{~b}$ ). This was in contrast to the GOD modified with 8-arm-PEG-NHS, which retained a lowered enzymatic activity after incubation at $\mathrm{pH}$ 5.1. This indicates that the cleavage of MAA linkages in acidic conditions led to almost complete recovery of the enzymatic activity, which can be attributed to the regeneration of unmodified proteins. Furthermore, the recovery of enzymatic activity after incubation at a mildly acidic $\mathrm{pH}$ was also observed with other enzymes (i.e., $\beta$ GAL and trypsin) that were modified with 8-arm-PEGMMA (Supporting Information, Figures S8 and S9), highlighting the versatility of this approach. Next, the enzymatic activity of GOD released from the GOD particles and GOD-loaded $\mathrm{CaCO}_{3}$ particles were compared. Both particles were degraded and free GOD was purified before the enzymatic activity measurements. Notably, the enzymatic activity of GOD released from the GOD particles was comparable to the GOD activity directly collected from the $\mathrm{CaCO}_{3}$ templates before cross-linking (Figure 4c), indicating the recovery of the enzymatic activity after the release from the GOD particles. Finally, the recovery of enzymatic activity inside cells was examined using $\beta$ GAL as a model enzyme and fluorescein $\operatorname{di}(\beta-D-$ galactopyranoside) (FDG) as a substrate. JAWS II cells were incubated with $\beta$-GAL particles cross-linked with either 8-arm-PEG-MMA or 8-arm-PEG-NHS, followed by the addition of FDG for enzymatic processing inside cells. The fluorescence from processed FDG was $80 \%$ stronger in cells treated with 8-arm-PEG-MMA cross-linked $\beta$-GAL particles compared with the cells treated with 8-armPEG-NHS cross-linked $\beta$-GAL particles (Figure $4 \mathrm{~d}$ ). There was also no significant difference in cellular interaction between the two types of particles (Supporting Information, Figure S1o). The enhanced enzymatic activity can be ascribed to the intracellular cleavage of the MAA linkage in response to acidic endosomal/lysosomal $\mathrm{pH}$, resulting in release of unmodified $\beta$-GAL and more efficient enzymatic reaction.

In summary, $\mathrm{pH}$-cleavable protein particles were prepared by cross-linking with an acid-labile cross-linker (8-
arm-PEG-MMA). The use of 8-arm-PEG-MMA allowed the preparation of protein particles from a series of proteins, which are sensitive to $\mathrm{pH}$ changes and disassemble at a mildly acidic $\mathrm{pH}$. The protein particles also disassembled inside cells. A major feature of 8-arm-PEG-MMA is the reversible modification of proteins. The model study using GOD indicated that the enzymatic activity was recovered $(\sim 97 \%)$ after cleavage of the MAA linkage at a mildly acidic $\mathrm{pH}$, which is attributed to the regeneration of unmodified proteins. This facile and versatile crosslinking strategy provides a novel approach to prepare protein particles, endowing them with a $\mathrm{pH}$-triggered disassembling mechanism that does not affect protein functionality. This approach may also be applied to enhance the delivery efficiency of various cargos, such as anticancer drugs, nucleic acids, vaccines and therapeutic proteins.
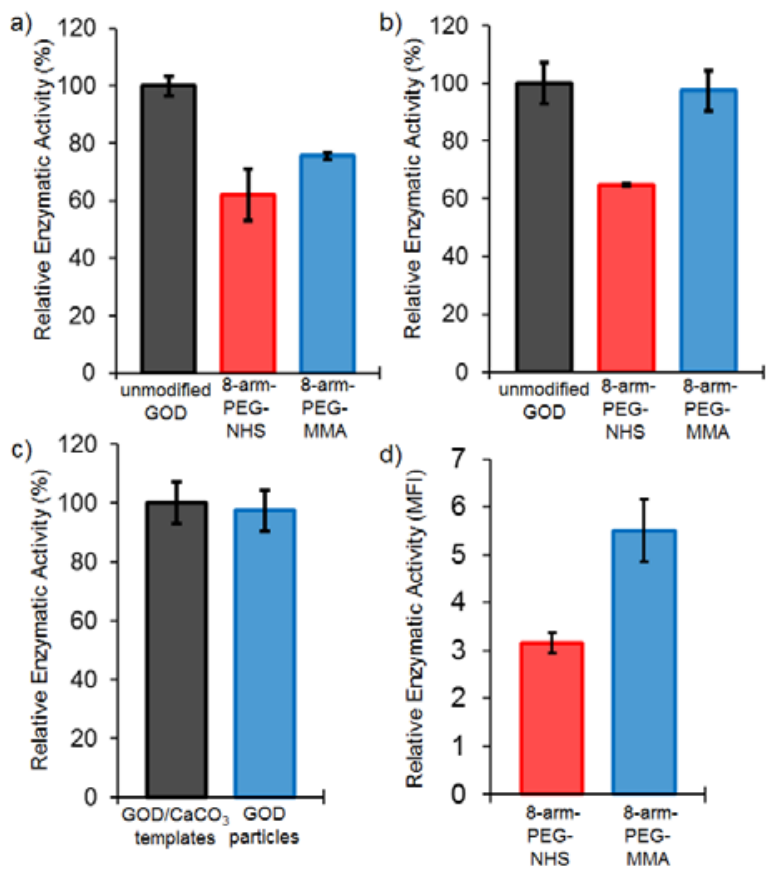

Figure 4. (a) Enzymatic activity of glucose oxidase (GOD) modified by 8-arm-PEG-MMA or 8-arm-PEG-NHS measured at $\mathrm{pH} 7.4$ and (b) after incubation at $\mathrm{pH}$ 5.1. (c) Enzymatic activity of GOD collected from GOD particles after incubation at $\mathrm{pH}$ 5.1, compared with GOD collected from the $\mathrm{CaCO}_{3}$ templates by treatment with EDTA. (d) Enzymatic activity of $\beta$-galactosidase ( $\beta$-GAL) inside JAWS II cells, which was delivered by $\beta$-GAL particles cross-linked by 8 arm-PEG-MMA or 8-arm-PEG-NHS. The results are expressed as the mean and standard deviation obtained from three samples.

\section{ASSOCIATED CONTENT}

\section{Supporting Information.}

Experimental methods, materials, and supplementary figures. This material is available free of charge via the Internet at http://pubs.acs.org.

\section{AUTHOR INFORMATION}

\section{Corresponding Author}


*E-mail: fcaruso@unimelb.edu.au.

\section{Author Contributions}

The manuscript was written through contributions of all authors.

\section{Notes}

The authors declare no competing financial interest.

\section{ACKNOWLEDGMENT}

This research was conducted and funded by the Australian Research Council Centre of Excellence in Convergent BioNano Science and Technology (project number CE140100036). This work was also supported by the Australian Research Council (ARC) under the Australian Laureate Fellowship (F.C., FL120100030), and Super Science Fellowship (F.C., FS110200025) schemes. M.M. is grateful to The University of Melbourne for a McKenzie Fellowship.

\section{REFERENCES}

(1) Ariga K.; Ji Q.; Mori T.; Yamauchi Y.; Abe H.; Hill J. P. Chem. Soc. Rev. 2013, 42, 6322-6345.

(2) Hawkins, M. J.; Soon-Shiong, P.; Desai, N. Adv. Drug Deliv. Rev. 2008, 6o, 876-885.

(3) Nitta, S. K.; Numata, K. Int. J. Mol. Sci. 2013, 14, 1629-1654.

(4) Tomlinson, I. M. Nat. Biotechnol. 2004, 22, 521-522.

(5) Xu, J.; Wang, J.; Luft, J. C.; Tian, S.; Owens, G.; Pandya, A. A.; Berglund, P.; Pohlhaus, P.; Maynor, B. W.; Smith, J.; Hubby, B.; Napier, M. E.; DeSimone, J. M. J. Am. Chem. Soc. 2012, 134, 87748777 .

(6) Xu, J.; Luft, J. C.; Yi, X.; Tian, S.; Owens, G.; Wang, J.; Johnson, A.; Berglund, P.; Smith, J.; Napier, M. E.; DeSimone, J. M. Mol. Pharm. 2013, 10, 3366-3374.

(7) Gallo, J. M.; Hung C. T.; Perrier, D. G. Int. J. Pharm. 1984, 22, 63-74.

(8) Müller, B. G.; Leuenberger, H.; Kissel, T. Pharm. Res. 1996, 13, 32-37.

(9) Lee, E. J.; Khan, S. A.; Park, J. K.; Lim, K-H. Bioprocess Biosyst. Eng. 2012, 35, 297-307.

(10) Lin, W.; Coombes, A. G. A.; Davies, M. C.; Davis, S. S.; Illum, L. J. Drug Targeting 1993, 1, 237-243.

(11) Langer, K.; Balthasar, S.; Vogel, V.; Dinauer, N.; von Briesen, H.; Schubert, D. Int. J. Pharm. 2003, 257, 169-180.

(12) Lee, S. H.; Heng, D.; Ng, W. K.; Chan, H. K.; Tan, R. B. H. Int. J. Pharm. 2011, 403, 192-200.

(13) Perry, J. L.; Herlihy, K. P.; Napier, M. E.; DeSimone, J. M. Acc. Chem. Res. 2011, 44, 990-998.

(14) Volodkin, D. V.; Schmidt, S.; Fernandes, P.; Larionova, N. I.; Sukhorukov, G. B.; Duschl, C.; Möhwald, H.; von Klitzing, R. Adv. Funct. Mater. 2012, 22, 1914-1922.

(15) Ariga K.; Yamauchi Y.; Rydzek G.; Ji Q.; Yonamine Y.; Wu K. C.-W.; Hill J. P. Chem. Lett. 2014, 43, 36-68.

(16) Tong, W.; Gao, C.; Möhwald, H. Colloid Polym. Sci. 2oo8, 286, 1103-1109.
(17) Mertz, D.; Wu, H.; Wong, J. S.; Cui, J.; Tan, P.; Alles, R.; Caruso, F. J. Mater. Chem. 2012, 22, 21434-21442.

(18) Wang, W.; Huang, Y.; Zhao, S.; Shao, T.; Cheng, Y. Chem. Commun. 2013, 49, 2234-2236.

(19) Veronese, F. M. Biomaterials 2001, 22, 405-417.

(20) Doretti, L.; Ferrara, D.; Gattolin, P.; Lora, S.; Schiavon, F.; Veronese, F. M. Talanta 1998, 45, 891-898.

(21) Treetharnmathurot, B.; Ovartlarnporn, C.; Wungsintaweekul, J.; Duncan, R.; Wiwattanapatapee, R. Int. J. Pharm. 20o8, 357, 252-259.

(22) De Groot, A. S.; Scott, D. W. Trends Immunol. 2007, 28, 482490.

(23) Pillay, C. S.; Elliott, E.; Dennison, C. Biochem. J. 2002, 363, 417-429.

(24) Elias, P. M. Semin. Immunopathol. 2007, 29, 3-14.

(25) Carmeliet, P.; Jain, R. K. Nature 2ooo, 407, 249-257.

(26) Kirby, A. J.; Lancaster, P. W. J. Chem. Soc., Perkin Trans. 2 1972, 1206-1214.

(27) Rozema, D. B.; Ekena, K.; Lewis, D. L.; Loomis, A. G.; Wolff, J. A. Bioconjugate Chem. 2003, 14, 51-57.

(28) Rozema, D. B.; Lewis, D. L.; Wakefield, D. H.; Wong, S. C.; Klein, J. J.; Roesch, P. L.; Bertin, S. L.; Reppen, T. W.; Chu, Q.; Blokhin, A. V.; Hagstrom, J. E.; Wolff, J. A. Proc. Natl. Acad. Sci. U.S.A. 2007, 104, 12982-12987.

(29) Lee, Y.; Ishii, T.; Cabral, H.; Kim, H. J.; Seo, J.; Nishiyama, N.; Oshima, H.; Osada, K.; Kataoka, K. Angew. Chem. Int. Ed. 2009, 48, 5309-5312.

(30) Maier, K.; Wagner, E. J. Am. Chem. Soc. 2012, 134, 1016910173 .

(31) Takemoto, H.; Miyata, K.; Hattori, S.; Ishii, T.; Suma, T.; Uchida, S.; Nishiyama, N.; Kataoka, K. Angew. Chem. Int. Ed. 2013, 52, 6218-6221.

(32) Petrov, A. I.; Volodkin, D. V.; Sukhorukov, G. B. Biotechnol. Prog. 2005, 21, 918-925.

(33) De Temmerman, M-L.; Demeester, J.; De Vos, F.; De Smedt, S. C. Biomacromolecules 2011, 12, 1283-1289.

(34) Ueno Y.; Futagawa H.; Takagi Y.; Ueno A.; Mizushima Y. J. Controlled Release 2005, 103, 93-98.

(35) Yamaoka, T.; Tabata, Y.; Ikada, Y. J. Pharm. Sci. 1994, 83, 601-6o6.

(36) Elsadek, B.; Kratz, F. J. Controlled Release 2012, 157, 4-28.

(37) Freiberg, S.; Zhu, X. X. Int. J. Pharm. 2004, 282, 1-18.

(38) Oyewumi, M. O.; Kumar, A.; Cui, Z. Expert Rev. Vaccines 2010, 9, 1095-1107.

(39) Merkel, T. J.; Chen, K.; Jones, S. W.; Pandya, A. A.; Tian, S.; Napier, M. E.; Zamboni, W. E.; DeSimone, J. M. J. Controlled Release 2012, 162, 37-44.

(40) Brossart, P.; Goldrath, A. W.; Butz, E. A.; Martin, S.; Bevan, M. J. J. Immunol. 1997, 158, 3270-3236.

(41) De Geest, B. G.; Willart, M. A.; Hammad, H.; Lambrecht, B. N.; Pollard, C.; Bogaert, P.; De Filette, M.; Saelens, X.; Vervaet, C.; Remon, J. P.; Grooten, J.; De Koker, S. ACS Nano 2012, 6, 21362149.

(42) Caruso, F.; Schüler, C. Langmuir 2ooo, 16, 9595-9603. 
Table of Contents

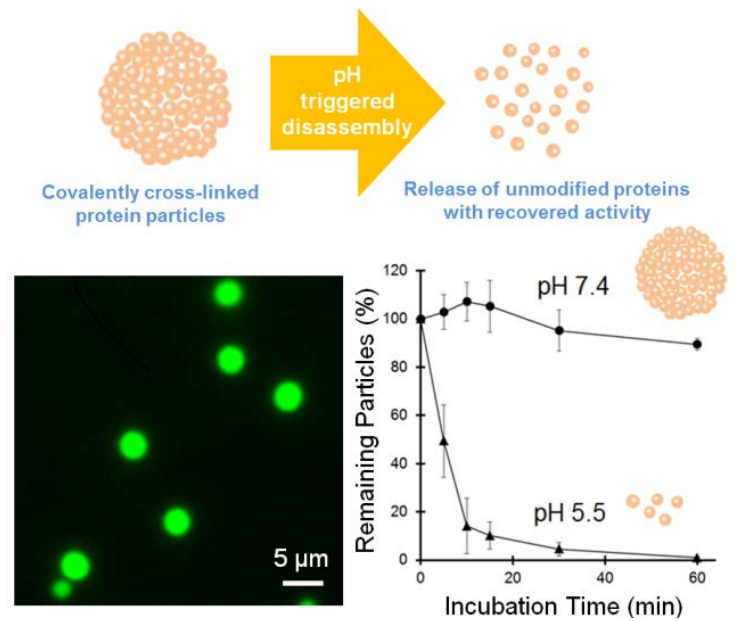




\section{University Library}

\section{- M M N E R VA A gateway to Melbourne's research publications}

Minerva Access is the Institutional Repository of The University of Melbourne

Author/s:

Suma, T;Cui, J;Muellner, M;Ju, Y;Guo, J;Hu, M;Caruso, F

Title:

Generalizable Strategy for Engineering Protein Particles with pH-Triggered Disassembly and Recoverable Protein Functionality

Date:

2015-02-01

Citation:

Suma, T., Cui, J., Muellner, M., Ju, Y., Guo, J., Hu, M. \& Caruso, F. (2015). Generalizable Strategy for Engineering Protein Particles with $\mathrm{pH}$-Triggered Disassembly and Recoverable Protein Functionality. ACS MACRO LETTERS, 4 (2), pp.160-164. https://doi.org/10.1021/ mz5007443.

Persistent Link:

http://hdl.handle.net/11343/90869 